\title{
CONTAMINAÇÃO MICROBIANA EM ERVA-MATE (Ilex paraguariensis)
}

\section{Claudio Rafael Kuhn ${ }^{1 *}$, Ricardo Peraça Toralles ${ }^{1}$, Bernardo dos Santos Vaz ${ }^{1}$, Michele Teresinha Ricardo Machado ${ }^{1}$}

${ }^{1}$ Instituto Federal Sul-Riograndense, Campus Pelotas, 96015-360, Pelotas, Rio Grande do Sul, Brasil

*Autor para correspondência: Claudio Rafael Kuhn; e-mail: crkuhn@ pelotas.ifsul.edu.br

Recebido: 05/10/2020, Aceito: 05/05/2021

\begin{abstract}
Resumo
Plantas como a erva-mate (Ilex paraguariensis) em geral contêm grande quantidade e diversidade de fungos e bactérias constituintes de sua própria microbiota natural. Estes micro-organismos podem advir do solo ou serem contaminadas durante o seu processamento, influenciando no grau de contaminação do produto e comprometendo a saúde do consumidor. Este trabalho teve como objetivo avaliar a contaminação microbiana da erva-mate comercializada no município de Pelotas/RS, através da determinação por micro-organismos indicadores como a quantificação de bactérias aeróbias mesófilas, a enumeração de bolores e leveduras, de coliformes (totais e termotolerantes) e presença de Salmonella spp. Analisaram-se diferentes amostras de erva, considerando como variáveis a marca, sua forma de comercialização (granel ou pacote de $500 \mathrm{~g}$ ) e apresentação (erva-mate in natura ou preparada como chimarrão - infusão a quente). Os resultados demonstraram comprometimento da qualidade das amostras, independente da marca, comercialização (granel ou pacote) ou apresentação. Houve uma redução da concentração microbiana na bebida pronta (chimarrão), mas em todos os casos, a contaminação fúngica e por bactérias mesófilas evidencia comprometimento nas condições higiênicas do produto, destacando-se ainda a presença de Salmonella em índices superiores a 50\% das amostras analisadas, indicando assim também risco sanitário.
\end{abstract}

Palavras-chave: Erva-mate; qualidade microbiológica, micro-organismos indicadores; contaminantes microbianos

\section{MICROBIAL CONTAMINATION IN MATE HERB (Ilex paraguariensis)}

\begin{abstract}
Plants such as mate herb (Ilex paraguariensis) in general contain a large amount and diversity of fungi and bacteria that come from your natural microbiota. These microorganisms may come from the soil or be contaminated during processing, influencing the degree of contamination of the product and compromising the health of the consumer. This study aimed to evaluate the microbial contamination of mate herb marketed in the Pelotas city (RS-Brazil) through the determination by indicator microorganisms such as the quantification of aerobic mesophilic bacteria, the enumeration of fungi (molds and yeasts), coliforms (total and thermotolerant) and the presence of Salmonella spp. Different herb samples were analyzed, and variables like brands, commercialization (bulk or $500 \mathrm{~g}$ pack), and presentation (herb natural or hot infusion) were studied. The results have demonstrated a low quality in all samples, regardless of the brand, commercialization, or presentation. There was a reduction in the microbial concentration in the hot infusions, but in all cases, contamination by fungi and mesophilic bacteria shows impairment in the hygienic conditions of the product. The presence of Salmonella in rates above $50 \%$ of the analyzed samples, also indicates a health risk for the product.
\end{abstract}

Keywords: Mate herb; microbiological quality; indicator microorganism; microbial contaminants 


\section{Introdução}

A erva-mate tem sua classificação botânica atribuída ao naturalista francês Auguste de Saint-Hilaire que, em uma viagem feita ao Brasil em 1822, coletou amostras as quais foram encaminhadas a Academia de Ciências do Instituto da França, onde foi registrada como Ilex paraguariensis. A planta compõe um dos sistemas de exploração agroflorestais mais antigos e característicos da Região Sul do Brasil, com ocorrência na região subtropical da América do Sul sendo nativa do Paraguai Oriental, Brasil Meridional e Argentina (FERRON, 2017; KUSSLER et al., 2004).

O produto erva-mate é obtido exclusivamente pelas folhas e ramos de Ilex paraguariensis, por processo de secagem e fragmentação e destinado ao preparo de bebidas típicas como "chimarrão" (infusão a quente) ou "tererê" (infusão a frio) com ou sem adição de açúcar. A alta variedade de compostos químicos presentes nas folhas da erva-mate tem despertado muitas pesquisas, que validam sua utilização como bebida. De acordo com Bracesco et al. (2011), nos últimos 15 anos a literatura relata muitos estudos relacionados a propriedades da Ilex paraguariensis como, por exemplo: propriedades antioxidantes, estimulantes, vasodilatadoras, redução de colesterol, efeitos antimutagênicos, propriedades de redução de peso, etc. A indústria tem demonstrado grande interesse na sua utilização, não somente para comercialização de bebidas, mas também no desenvolvimento de produtos farmacêuticos, cosméticos e de higiene. Dentre esses compostos já relatados para a espécie Ilex, pode-se destacar a presença de vitaminas, minerais, saponinas, ácido fólico, metilxantinas, taninos, carotenoides, entre outros metabólitos secundários (BRACESCO et al., 2011; GNOATTO et al., 2008; PAGLIOSA, 2009).

Os aspectos fundamentais da qualidade da ervamate são: a identidade do produto, qualidade microbiológica, toxicologia, composição físicoquímica adequada e características sensoriais. O estabelecimento de critérios e controle microbiológico constante é indispensável para a produção de um alimento/produto seguro. É importante que produtos como a erva-mate sejam avaliados constantemente, haja vista que um dos contaminantes mais frequentes de plantas e produtos desidratados sejam os fungos, agentes causadores de várias intoxicações, com ausência de padrões previstos na legislação (FERRON, 2017; BARBOZA et al, 2006).

A presença de micro-organismos indicadores reflete a qualidade no processamento de alimentos em relação à sua vida útil e segurança alimentar, constituindo uma indicação de contaminação elevada de matérias-primas, no processamento ou etapas pós-processo, evidenciando práticas de higiene e sanificação fora dos padrões requeridos no processamento de alimentos (FRANCO, LANDGRAF, 2008; SILVA et al., 2017).

Apesar de um processamento aparentemente simples quando comparada às demais agroindústrias, ainda há muito a ser estudado e aprimorado na cadeia de operações para cultivo e obtenção de erva-mate, devido à incidência frequente de contaminantes microbianos nesse alimento, o que caracteriza potencial situação de risco à saúde pública. Assim, o objetivo deste trabalho foi avaliar a contaminação microbiana em amostras de erva-mate (Ilex paraguariensis) considerando diferentes marcas, forma de comercialização (granel e pacote) e apresentação (erva in natura ou bebida pronta, chimarrrão), através das contagens de mesófilos, fungos, enumeração de coliformes (totais e termotolerantes) e presença de Salmonella sp.

\section{Material e Métodos}

As amostras de oito marcas de erva-mate in natura (quatro comercializadas a granel com peso de $500 \mathrm{~g} \mathrm{e}$ quatro comercializadas em pacotes de $500 \mathrm{~g}$ ) foram adquiridas no comércio local, na cidade de Pelotas, RS, área urbana, sendo estas amostras transportadas isotermicamente ao Laboratório de Microbiologia do Curso Técnico em Química do IF Sul-rio-grandense, para condução das análises microbiológicas (triplicatas) tanto da erva-mate in natura como do seu chimarrão (infusão a quente, preparado com água a $70^{\circ} \mathrm{C}$ ).

As amostras (25 g) foram homogeneizadas em 225 $\mathrm{mL}$ de solução salina $0,85 \%$ (diluente) em homogeneizador tipo Stomacher (Marconi MA 440), durante $120 \mathrm{~s}$, constituindo assim a primeira diluição decimal $\left(10^{-1}\right)$; dessa mistura, retirou-se uma alíquota de 1,0 mL e transferiu-se para 9,0 $\mathrm{ml}$ do diluente em tubo de ensaio para a obtenção da segunda diluição decimal $\left(10^{-2}\right)$, repetindo-se o procedimento, a partir desta última, para o preparo da terceira diluição $\left(10^{-3}\right)$. Todas as amostras foram submetidas a análises quanto a presença de Salmonella spp.; enumeração de bactérias mesófilas; de bolores e leveduras; de coliformes totais e termotolerantes (DOWNES, ITO, 2001; SILVA et al., 2017).

A detecção de Salmonella utilizou um préenriquecimento em solução salina $0,85 \%$ com incubação $\left(24\right.$ horas a $\left.35^{\circ} \mathrm{C}\right)$, seguida de repicagem para meios de enriquecimento seletivo em caldo Rapapportt Vassiliadis, caldo Tetrationato (suplementado com solução Iodo e de Verde brilhante) e caldo Selenito Cistina, com incubação a 24 horas a $42^{\circ} \mathrm{C}$ para o primeiro e para os demais a 24 horas a $35^{\circ} \mathrm{C}$. Após, seguiu-se o plaqueamento diferencial nos ágares Xilose Dextrose (XLD) e Hecktoen (HE), incubados por 24 horas a $35^{\circ} \mathrm{C}$, seguido de testes bioquímicos preliminares nos ágares Lisina (LIA), Tríplice açúcar e 
ferro (TSI) e testes bioquímicos complementares em ágar citrato e caldo ureia (teste de urease) novamente com incubação $\left(24\right.$ horas a $\left.35^{\circ} \mathrm{C}\right)$; finalmente, a confirmação foi obtida pelo teste sorológico polivalente somático pela técnica de aglutinação em lâmina.

A contagem de bactérias mesófilas realizou-se através de semeadura tipo spread plate em Ágar Padrão de Contagem (Plate Count Agar, PCA) seguida de incubação $\left(35^{\circ} \mathrm{C}\right.$ por 48 horas) e contagem, sendo os resultados expressos em Unidades Formadoras de Colônias/mL (UFC/mL).

$\mathrm{Na}$ enumeração dos bolores e leveduras realizou-se a inoculação spread plate em placas com Ágar Batata Dextrose (Potato Dextrose Agar, PDA) acidificado com ácido tartárico $10 \%$ e incubação a $25 \pm 1^{\circ} \mathrm{C}$, por cinco a sete dias, sendo os resultados expressos em UFC/mL.

Para a enumeração de coliformes totais e termotolerantes utilizou-se a técnica do Número Mais Provável (NMP/mL), com tubos múltiplos em série de três tubos por diluição. A análise presuntiva de coliformes utilizou o meio Caldo Lauril Sulfato de Sódio, com incubação por 48 horas a $35^{\circ} \mathrm{C}$ e a confirmação realizada em Caldo Lactosado Bile Verde Brilhante, incubado por 24 a 48 horas a $35^{\circ} \mathrm{C}$ para coliforme totais; a enumeração de coliformes termotolerantes utilizou o Caldo Escherichia Coli, com incubação a $44-45^{\circ} \mathrm{C}$ durante 24 horas.

$\mathrm{O}$ delineamento experimental considerou a contaminação microbiana por indicadores como variável dependente (resposta). Os tratamentos (variáveis independentes) considerados foram: a) marca (8); b) apresentação: como erva in natura ou chimarrão (infusão a quente, preparada com água a $70^{\circ} \mathrm{C}$ ); e c) comercialização: a granel e acondicionada (pacote de $500 \mathrm{~g}$ )., totalizando 32 tratamentos. Os resultados das análises microbianas (triplicatas) foram logaritmizados e analisados estatisticamente através de uma análise de variância (ANOVA), seguida do teste de Tukey, para comparações múltiplas de médias $(P<0,05)$, enquanto os dados da análise de Salmonella sp. foram analisados por estatística descritiva (PIMENTEL-GOMES, 2009).

\section{Resultados e Discussão}

O perfil dos níveis de contaminação apresentados nas amostras de erva-mate in natura foi bem distinto entre os indicadores pesquisados. (Fig. 1), independente da forma de comercialização (pacotes ou granel) ou da marca. Verificou-se em todos esses casos que os indicadores microbianos como fungos e mesófilos apresentaram maiores concentrações $(P<0,05)$ em relação ao grupo coliforme, este último em níveis baixos e sem diferença entre o grupo total e termotolerante.
Quando comparada a contaminação entre a ervamate in natura e o chimarrão (infusão a quente, preparado com água a $70^{\circ} \mathrm{C}$ ), independente da marca ou forma de comercialização (Fig. 2), observou-se uma redução nos níveis de todos os indicadores. Contudo essa diminuição foi significante $(P<0,05)$ apenas para o grupo coliforme (tanto para coliformes totais como para termotolerantes), enquanto para contaminantes fúngicos e bactérias mesófilas, não foi constatado mesmo perfil de redução na contaminação desses indicadores microbianos.

$\mathrm{Na}$ análise de Salmonella, o isolamento da bactéria (confirmada em testes bioquímicos e por aglutinação em lâmina) foi confirmado tanto para amostras de ervamate in natura como para o chimarrão. A preparação do chimarrão (infusão a quente) com as amostras de ervamate analisadas apresentou altos índices de redução na detecção da bactéria, tanto para sua comercialização a granel como em pacotes de $500 \mathrm{~g}$ (Fig. 03). Embora com redução, não se verificou ausência da bactéria em todas as amostras e esse resultado indica que mesmo na temperatura da água a $70^{\circ} \mathrm{C}$, considerada ideal para ingestão da infusão a quente, a bactéria pode permanecer viável e assim representar risco ao consumidor.

A Resolução da Diretoria Colegiada - RDC n ${ }^{\circ} .12$, de 2 de janeiro de 2001, da Secretaria Nacional de Vigilância Sanitária do Ministério da Saúde, estabelece para chá e produtos similares, obtidos por processamento térmico (torração e processos similares), consumidos após tratamento térmico (infusão e decocção), com ou sem adição de açúcar e outros ingredientes, ausência de Salmonella spp. em $25 \mathrm{~g}$ de amostra e limite máximo de $5 \times 10^{3} \mathrm{NMP} / \mathrm{g}$ para coliformes a $45^{\circ} \mathrm{C}$ (BRASIL, 2001). A produção e comercialização do produto no país é regulamentada pelo Ministério da Saúde, Divisão de Alimentos (Portaria 464/97) e os critérios de qualidade encontramse fixados na Resolução $n^{\circ}$ 302, de 07 de novembro de 2002, do Ministério da Saúde (BRASIL, 2002). Já a Organização Mundial de Saúde - OMS, estabelece para chás consumidos na forma de infusão ou decocto as contagens de bactérias mesófilas com limite máximo de $10^{7} \mathrm{UFC} / \mathrm{g}$, e de bolores e leveduras com limite máximo de $10^{4} \mathrm{UFC} / \mathrm{g}$ (WORLD HEALTH ORGANIZATION, 2000).

Os vegetais podem conter um grande número de fungos e bactérias provenientes do solo, pertencentes à microflora natural das plantas ou mesmo contaminados durante o processamento e a manipulação. As condições durante manejo, secagem e armazenamento influenciam nos resultados para a contagem microbiológica do produto. Outros fatores relacionados com a alteração na qualidade microbiológica de forma indesejável correspondem à presença de condições inadequadas no 
transporte e na estocagem e manipulação do produto final (BERTÉ et al., 2006).

$\mathrm{O}$ crescimento microbiano é fator preponderante na manutenção da qualidade de alimentos. A erva-mate é um produto desidratado, sendo enquadrada na categoria dos alimentos não perecíveis, sendo estocados à temperatura ambiente. As deteriorações de origem microbiana em alimentos dependem de fatores intrínsecos e extrínsecos. Os fatores intrínsecos são inerentes ao substrato e os principais são a atividade água, o pH e a composição química do alimento. Os fatores extrínsecos são os que dependem das condições externas ao substrato, como umidade relativa, temperatura e oxigênio atmosférico (FRANCO \& LANDGRAF, 2008; RENOVATTO \& AGOSTINI, 2008).

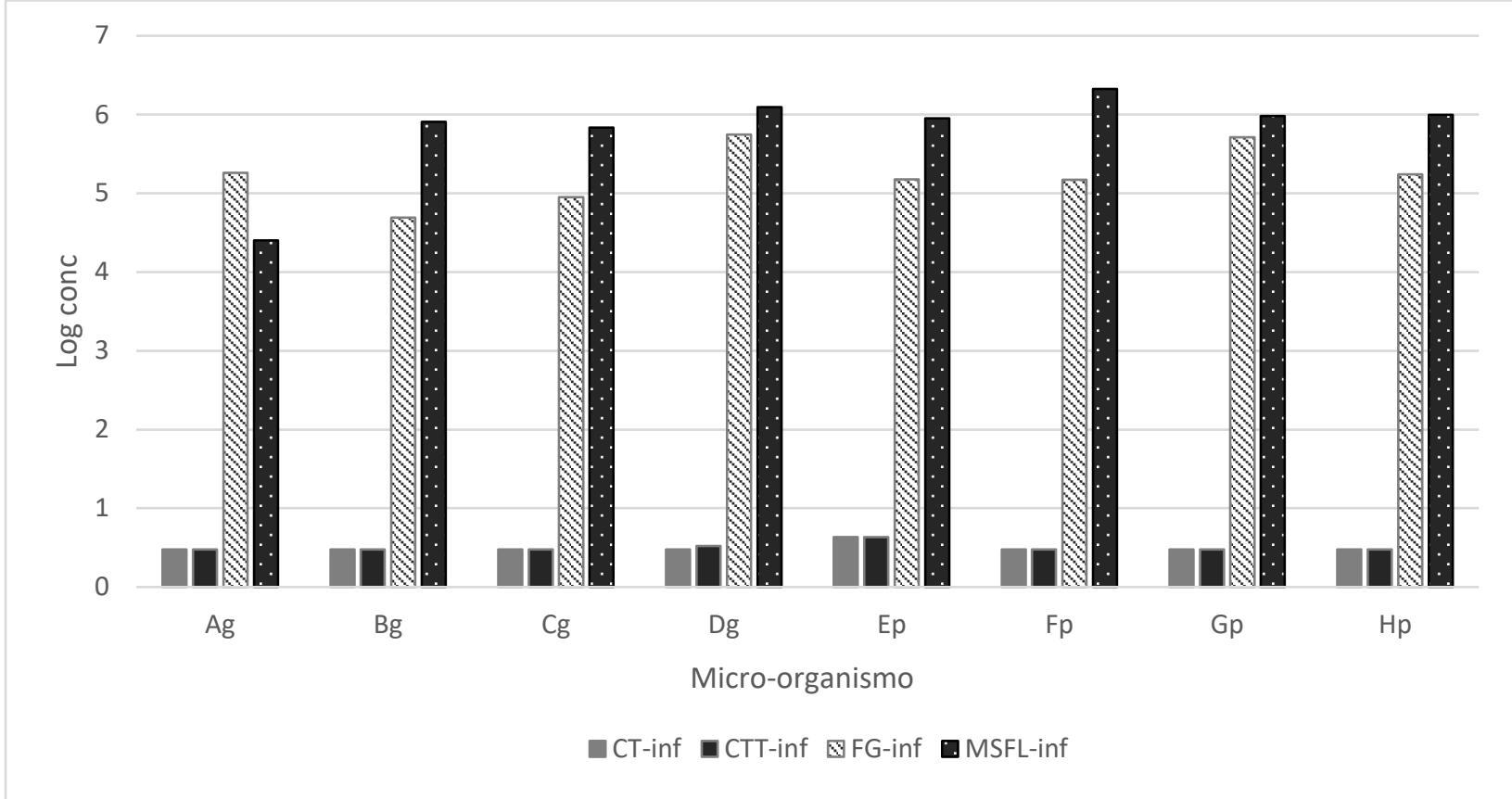

Fig. 1 - Contaminação (log) de erva-mate por indicadores em diferentes marcas (A-H) considerando o tipo de apresentação ( $\mathrm{g}$ - granel; $\mathrm{p}$ - pacotes de $500 \mathrm{~g}$ ).

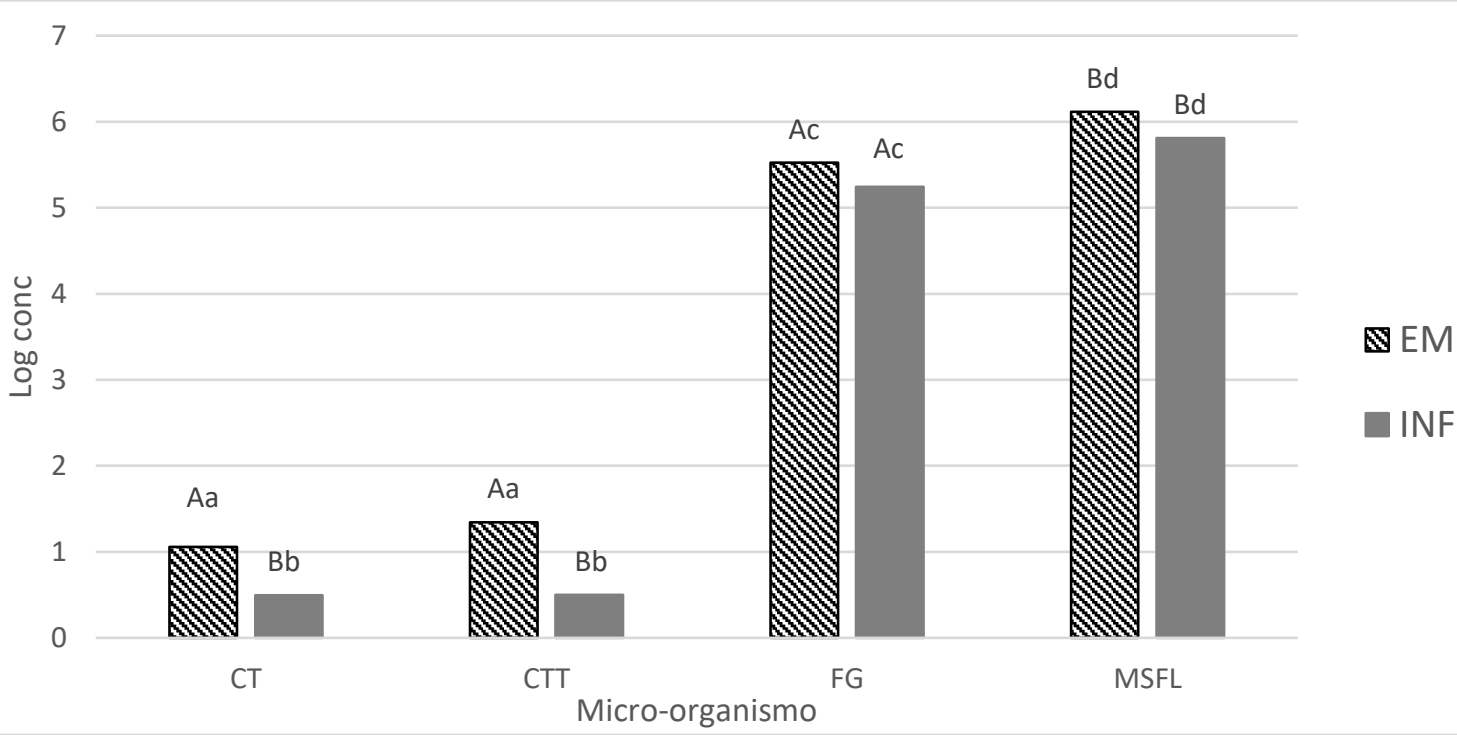

Fig. 2 - Comparação da contaminação (log) por indicadores em erva-mate in natura (1) e chimarrão (2); $\mathrm{Ct}$ - coliformes totais; CTT - coliformes termotolerantes; FG - fungos; MSFL - bactérias mesófilas. Letras maiúsculas nas colunas indicam diferença nos indicadores na erva-mate in natura (1) e na infusão (2) separadamente; letras minúsculas nas colunas indicam diferença entre erva-mate in natura (1) e chimarrão (2) para cada micro-organismo indicador. 
A Salmonella - Erva mate (a granel)

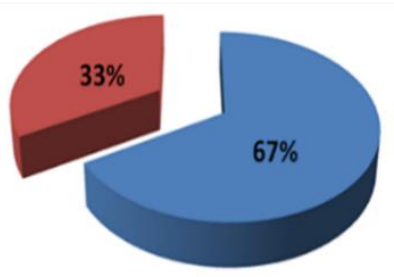

C Salmonella - Erva mate (envasado)

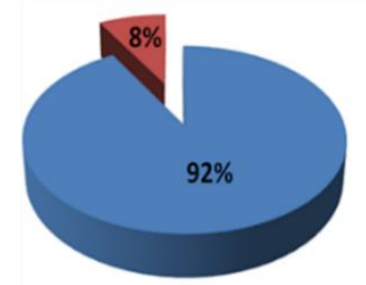

B Salmonella - Infusão (a granel)

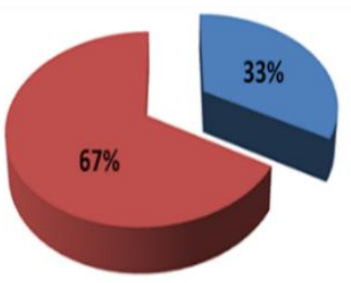

D Infusão (envasado)

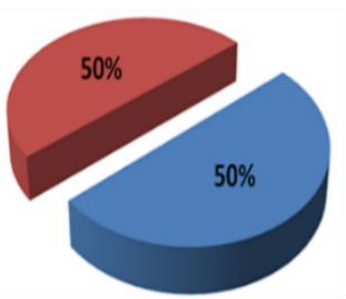

presença

ausência

Fig. 3-Comparação da presença de Salmonella entre amostras de erva-mate in natura e chimarrão (infusão a quente). A - Erva-mate in natura a granel e B - Infusão (granel); C - Erva-mate in natura em pacotes de 500 g e D - Infusão (pacotes de 500 g). Azul: presença; vermelho: ausência.

Mesmo com os resultados da contagem de mesófilos em conformidade com o padrão, a elevada presença de bolores e leveduras significa um comprometimento das condições higiênicas do produto. A contagem de bolores e leveduras é necessária e útil para indicar a deterioração do alimento e verificar se as normas de higiene durante a manipulação e armazenamento do produto estão sendo respeitadas (RENOVATTO; AGOSTINI, 2008). A sua elevada presença nas amostras pode ser atribuída, possivelmente, a condições inadequadas de estocagem e comercialização, devido ao efeito sinérgico dos fatores extrínsecos acima citados; à exposição do produto ao ambiente, no caso da comercialização a granel e também às condições de embalagem precárias, muitas vezes em papel, com falhas nas soldas, dobraduras e até mesmo fissuras, no caso do produto em pacotes.

Em relação ao grupo coliforme, todas as amostras estiveram em conformidade com a legislação vigente. A sua presença é um importante indicativo de manipulação incorreta e falta da aplicação de procedimentos de Boas Práticas de Fabricação (BPF), podendo inclusive ser considerado um indicativo de contaminação de origem fecal, no caso do grupo termotolerante, evidenciando assim, risco para a saúde dos consumidores quando detectado nas amostras (PINTO et al., 2011).

A erva-mate pode sofrer alterações durante sua estocagem devido ao crescimento microbiano em função da absorção de umidade, condição essa que favorece grandemente aos fungos, como observado nas amostras deste experimento. Essa situação é corroborada por Bernardi et al. (2005) que analisaram 34 amostras de erva-mate e encontraram fungos dos gêneros Aspergillus sp. e Penicillium sp. como contaminantes. Borges et al. (2002) em experimento muito similar ao aqui relatado, mas isolando gêneros fúngicos, constataram a presença de Aspergillus sp. $(62,13 \%)$, Penicillium sp. (32,35\%) e Rhizopus sp. $(5,52 \%)$, sendo os dois primeiros considerados potencialmente micotoxigênicos e o último considerado um contaminante comumente encontrado em alimentos. Vale destacar que as micotoxinas, dependendo da quantidade ingerida, podem ser nocivas à saúde humana, vindo a ser carcinogênicas ou hepatóxicas (BERNARDI et al., 2005).

Avaliando a contagem de fungos no controle de qualidade da erva-mate comercializada em Curitiba-PR, Nietsche (2002) detectou bolores e leveduras acima do permitido pela Resolução-RDC n.12 (BRASIL, 2001), em duas das cinco amostras analisadas, revelando níveis de contaminação bastante similares ao trabalho aqui relatado.

$\mathrm{Na}$ caracterização microbiológica em erva-mate cancheada (aquela que não passa pela moagem final), Burgardt (2000) encontrou uma população <3 NMP/g, para coliformes fecais e uma população de $6,0 \mathrm{x}$ $10^{2} \mathrm{UFC} / \mathrm{g}$ para bolores e leveduras e ausência de Salmonella no produto. Similarmente, Fracaro (2014) analisando cinco marcas de erva comercializadas na mesma cidade, não detectou alterações padrões microbiológicos analisados, estando todas as marcas em conformidade, assim como relatado por Freitas et al 
(2006), que comparou a qualidade microbiológica de tipos de erva-mate cancheada verde e tostada.

A qualidade microbiológica de 50 amostras de ervamate cancheada de diferentes indústrias ervateiras analisadas por Bordenave et al. (2003) apresentou contaminação variável por bactérias mesófilas $\left(<10^{2}\right.$ até $\left.10^{5} \mathrm{UFC} / \mathrm{g}\right)$, bolores e leveduras $\left(2 \times 10^{1}\right.$ e $\left.4 \times 10^{4} \mathrm{UFC} / \mathrm{g}\right)$ e coliformes totais ( $<3$ e $12 \times 10^{3} \mathrm{NMP} / \mathrm{g}$ ), não sendo detectados coliformes termotolerantes. Em nove amostras de erva-mate avaliadas durante seis meses, Hermes e Hanefeld (2001) encontraram valores médios de 5,0x $10^{3} \mathrm{UFC} / \mathrm{g}$ para bolores e leveduras, e ausência do grupo coliforme e Salmonella sp. Já Parodes et al. (2014) estudando amostras de erva cancheada encontrou variações na contagem de mesofilos no produto final, salientando a importância de manter estudos envolvendo as agroindústrias e o processamento para garantir segurança ao consumidor e à saúde pública.

Segundo Lima (2005), o perigo para a saúde do consumidor da erva-mate é a multiplicação de microorganismos patogênicos como Salmonella spp. e coliformes termotolerantes que podem estar presentes na erva-mate in natura e sobreviver durante $\mathrm{o}$ processamento ou mesmo na sua infusão.

$\mathrm{Na}$ produção de uma erva-mate para de boa qualidade é indispensável que todas as etapas da cadeia de produção tenham procedimentos adequados para garantir uma redução da contaminação a níveis aceitáveis. Cuidados com a matéria-prima, boas práticas agrícolas desde o manejo no campo, em etapas como corte, coleta e transporte. O processo de beneficiamento da erva-mate pode reduzir a carga microbiana inicial, mas nem sempre de uma maneira que seja suficientemente segura para o consumidor. Finalmente, no comércio, devem ser conhecidos procedimentos higiênicos e condutas de manipulação e estocagem do produto que garantam a manutenção dos baixos níveis de contaminação microbiana. A contaminação verificada nas amostras de erva-mate analisadas expõe a carência de uma uniformidade de procedimentos que garantam segurança microbiológica tanto na cadeia de produção como na de comercialização do produto.

\section{Conclusão}

As amostras analisadas de erva-mate apresentaramse dentro dos padrões exigidos pela legislação vigente quanto a mesófilos e para o grupo coliformes; contudo foi detectada inconformidade devido à elevada contaminação por fungos e pela presença de Salmonella spp., (67\% na erva-mate a granel e $92 \%$ na erva em pacotes).Sob a forma de infusão, verificou-se uma redução na contaminação, mas não a ponto de atender aos parâmetros da legislação e garantir segurança ao consumidor, devido à presença de Salmonella spp. e de fungos ainda em concentração elevada.

\section{Agradecimentos}

Ao $\mathrm{CNPq}$ e ao curso de química do IFSUL Campus Pelotas, respectivamente, pela concessão da bolsa de estudos e estrutura para a realização do trabalho.

\section{Referências}

BARBOZA, L. M. V., WASZCZYNSKYJ, N., de FREITAS, R. J. S. Avaliação microbiológica de ervamate (Ilex paraguariensis St. Hil.). Revista do Instituto Adolfo Lutz, 65(2):123-126, 2006

BERNARDI, E.; CALDEIRA, F. M.; NASCIMENTO, J. S. Identificação de fungos filamentosos em erva-mate (Ilexparaguariensis St. Hil.). Arquivos do Instituto Biológico. São Paulo, v.72, n.4, p.489-493, out./dez., 2005.

BERTÉ, S. A. K. et al. Vida-de- prateleira: microbiologia da erva-mate chimarrão. Acta Farmacéutica Bonaerense, v.25, n.1, p. 95-8, 2006.

BORDENAVE A. S. et al. Correlacion de lascenizas y humedad de hojas de yerba mate y la calidad microbiologica de yerba mate canchada estacionada. In: $3^{\circ}$ Congresso Sul-Americano da Erva-Mate. Chapecó: $1^{\text {a }}$ Feira do Agronegócio de Erva-Mate, 2003: 26-32.

BORGES L.R. et al. Contagem de fungos no controle de qualidade da erva-mate (Ilex paraguariensis St. Hil.) e isolamento de gêneros potencialmente micotoxigênicos. Boletim do CEPPA, v.20 n.1, p.103110. 2002.

BRACESCO, N. et al. Recent advances on Ilex paraguariensis research: Minireview. Journal of Ethnopharmacology, v.136, p. 378-384, 2011.

BRASIL. Ministério da Saúde. Resolução RDC n. 12, de 2 de janeiro de 2001. Regulamento técnico sobre padrões microbiológicos para alimentos. Diário Oficial [da] República Federativa do Brasil, Brasília, DF, 2 de Jan. 2001. p.1-6.

BRASIL. Ministério da Saúde. Resolução RDC n. 302, de 07 de novembro de 2002. Dispõe sobre o regulamento técnico para fixação de identidade e qualidade para erva-mate. Diário Oficial [da] República Federativa do Brasil, Brasília, DF, 08 de nov. 2002. p.50. 
BURGARDT A. C. Desenvolvimento de uma bebida utilizando extrato de erva-mate (Ilex paraguariensis St. Hil.) 2000. 133p. Dissertação (Mestrado em Tecnologia de Alimentos) Universidade Federal do Paraná. Curitiba, 2000. 133 pp.

DOWNES, F. P.; ITO, K. Compendium of Methods for the Microbiological Examination of Foods. $4^{\text {th }} \mathrm{ed}$. Washington: American Public Health Association, 2001.

FERRON, R. M. Avaliação microbiológica de ervamate (Ilex Paraguariensis st. Hilaire) utilizada no preparo do chimarrão comercializada no município de Dois vizinhos - PR. 2017. 20p. Trabalho de conclusão de curso (TCC) Curso Superior de Agronomia da Universidade Tecnológica Federal do Paraná -UTFPR, Dois Vizinhos, 2017.

FRACARO, L. Qualidade de erva-mate (Ilex paraguariensis A. ST-HIL) para chimarrão comercializada na cidade de Cascavel, PR, Brasil. Revista Varia Scientia Agrarias, v.4, n.1, p. 39-47, 2014.

FRANCO, B. D. G. M.; LANDGRAF, M. Microbiologia dos alimentos. Ed Atheneu, 2008.

FREITAS, R. J. S.; WASZCZYNSKYJ, N.; BARBOZA, L. M. V. Avaliação microbiológica de erva-mate (Ilex paraguariensis St. Hil.). Revista do Instituto Adolfo Lutz, v.65, n.2, p.123-126, 2006.

GNOATTO S. C., et al. Evaluation of ursolicacid isolated from Ilex paraguariensis and derivatives on aromatase inhibition. European Jornal of Medical Chemistry .v.43, p. 1865-1877, 2008.

HERMES, N.; HANEFELD, A. O. Avaliação da qualidade da erva-mate produzida com tecnologia desenvolvida para escala de microindústria. TecnoLógica, Santa Cruz do Sul, v.5, n.1, p.9-27, 2001.

KUSSLER, A. L. et al. Primeiro registro da Cochonilla pendularia paraguariensis Granara de Willink,1999 (Hemíptera, Coccidae) no Brasil. Ciência Rural, v.34, n.4, p.1231-1233, 2004.

LIMA, D. P. Sistema de análise de perigos e pontos críticos de controle na indústria de erva-mate: uma visão da nova economia institucional. 2005. Dissertação (Mestrado em Desenvolvimento Regional e Agronegócio) - Universidade Estadual do Oeste do Paraná, Toledo, 2005.
NIETSCHE, K. Caracterização da qualidade da erva-mate cancheada. 2002. 96f. Dissertação (Mestrado em Tecnologia Química) - Universidade Federal do Paraná. Curitiba, 2002.

PAGLIOSA C. M. Caracterização química do resíduo de ervais e folhas "in natura" de erva-mate (Ilex paraguariensis A. St. Hil.). 2009. 143 p. Dissertação (Mestrado em Ciência dos Alimentos) Programa de Pós-Graduação em Ciência dos Alimentos, Universidade Federal de Santa Catarina. Florianópolis. 2009.

PARODES, B. M. et al. Caracterização Microbiológica de Erva-Mate (Ilex paraguariensis St. Hil.) Beneficiada Na Região do Médio Alto Uruguai - RS. In: XII Congresso Latino Americano de Microbiologia e Higiene de Alimentos. v.01, Nov, 2014.

PIMENTEL-GOMES, F. P. Curso de Estatística Experimental. Piracicaba, ESALQ, 2009.

PINTO, F. G. S. et al. Qualidade Microbiológica de queijo minas frescal comercializado no município de Santa Helena, PR, Brasil. Arquivos do Instituto Biológico, São Paulo, v.78, n.2, p.191-198, abr./jun., 2011.

SILVA, N. et al. Manual de Métodos de Análise Microbiológica de Alimentos. $5^{\mathrm{a}}$ Ed. São Paulo; Blucher, 2017.

RENOVATTO, P. Y.; AGOSTINI, J. Qualidade microbiológica e físico-química de amostras de ervamate (Ilex paraguariensis) comercializadas em Dourados, MS. Interbio, v.2, n.2, 2008.

WORLD HEALTH ORGANIZATION. Quality control methods for medical plant materials. Geneva: WHO; 2000. 115 p. 